\title{
Control of Zinc-containing Dust Agglomerates in Basic Oxygen Furnace Flue Gas Cleaning System
}

\author{
Xiang $\mathrm{LI}^{1,2)}$ Ping TANG, ${ }^{1,2) *}$ Jing JIANG, ${ }^{1,2)}$ Qu FU ${ }^{1,2)}$ and Guanghua WEN ${ }^{1,2)}$ \\ 1) College of Materials Science and Engineering, Chongqing University, Chongqing, 400044 P. R. China. \\ 2) Chongqing Key Laboratory of Vanadium-Titanium Metallurgy and New Materials, Chongqing University, Chongqing, 400044 \\ P. R. China.
}

(Received on October 12, 2020; accepted on November 25, 2020)

\begin{abstract}
Basic oxygen furnace (BOF) flue gas cleaning system is a crucial flue gas purification device to ensure the cleaner production in steelmaking process. Due to utilization of galvanized steel scrap in steelmaking process, zinc-containing dust collected by the cleaning system forms unremovable high-strength dust agglomerates on the inner wall of evaporative cooler, which can affect the normal operation of cleaning system and seriously hinder the cleaner production in steelmaking process. This issue continuously aggravates as the use of galvanized steel scrap increases, while there are currently no effective control methods. Consequently, how to keep down the zinc-containing dust agglomeration strengthening in the evaporative cooler is a crucial issue for investigation. In this paper, X-ray fluorescence spectrometer, X-ray diffraction, scanning electron microscopy and strength test under high-temperature roasting were carried out to investigate characteristics and strengthening mechanism of dust agglomerates. Based on this, easy implementation of control methods were proposed. The results show that $\mathrm{ZnO}$ reacts with $\mathrm{Fe}_{2} \mathrm{O}_{3}$ at a high temperature above $600^{\circ} \mathrm{C}$ to form tightly $\mathrm{ZnFe}_{2} \mathrm{O}_{4}$ phase, and chemical adsorption of $\mathrm{ZnFe}_{2} \mathrm{O}_{4}$ with $\mathrm{BOF}$ dust particles is the primary cause of dust agglomeration strengthening in evaporative coolers. Solid state sintering of low melting point substances containing $\mathrm{Na}^{+}$and $\mathrm{K}^{+}$promotes strengthening. Decreasing the temperature in evaporative cooler and controlling the content of low melting point substances in BOF dust are effective measures to reduce dust agglomerates, optimize the environment of cleaning system, and ensure the cleaner production in steelmaking process.
\end{abstract}

KEY WORDS: basic oxygen furnace; flue gas cleaning system; evaporative cooler; zinc-containing dust; agglomeration; cleaner production.

\section{Introduction}

In the metallurgical process of contemporary world, basic oxygen furnace (BOF) steelmaking is the uppermost method. According to World Steel Association, about 70\% of the total steel worldwide is produced by BOF, especially, about $90 \%$ of the total steel in China. ${ }^{1)}$ In steelmaking, basic oxygen furnaces can generate a large quantity of flue gas solid wastes, referred to as BOF dust, from 10 to $30 \mathrm{~kg}$ per metric ton of steel $(\mathrm{kg} / \mathrm{ts})$, and the dust concentration is between 150 and $300 \mathrm{~g}$ per cubic meter $\left(\mathrm{g} / \mathrm{m}^{3}\right)$.

In 2019, crude steel production was 996 million tons in China, and 1869 million tons worldwide. ${ }^{1)}$ According to average output of BOF dust $20 \mathrm{~kg} / \mathrm{ts}$, it can be estimated that in 2018 generation was around 18 million tons in China alone and up to 36 million tons globally. Due to the tiny particle size of BOF dust, it is wafted in the atmosphere,

\footnotetext{
* Corresponding author: E-mail: tping@cqu.edu.cn
}

not only pollutes the environment, but also affects human health, causing or exacerbating pulmonary diseases. ${ }^{2-4)}$ Therefore, it is particularly vital to select suitable BOF flue gas cleaning equipment to collect these solid wastes.

BOF flue gas cleaning system is an important equipment to ensure the cleaner production in steelmaking process. It is mainly divided into dry and wet systems. ${ }^{5)}$ The dust concentration in BOF wet flue gas cleaning system is generally 100 $\mathrm{mg} / \mathrm{m}^{3}$, while BOF dry cleaning system is less than $10 \mathrm{mg} /$ $\mathrm{m}^{3}$. According to an emission standard of air pollutants for steel smelt industry issued by the Ministry of Ecology and Environment of China, the emission concentration limit of particulate matter in BOF flue gas is $50 \mathrm{mg} / \mathrm{m}^{3}$. Obviously, the dry flue gas cleaning system can satisfy the requirements of current steelmaking cleaner production. Furthermore, compared with BOF wet flue gas cleaning system, the dry flue gas cleaning system consumes less electricity and has no secondary pollution. ${ }^{6,7)}$

As shown in Fig. 1, BOF dry flue gas cleaning system 


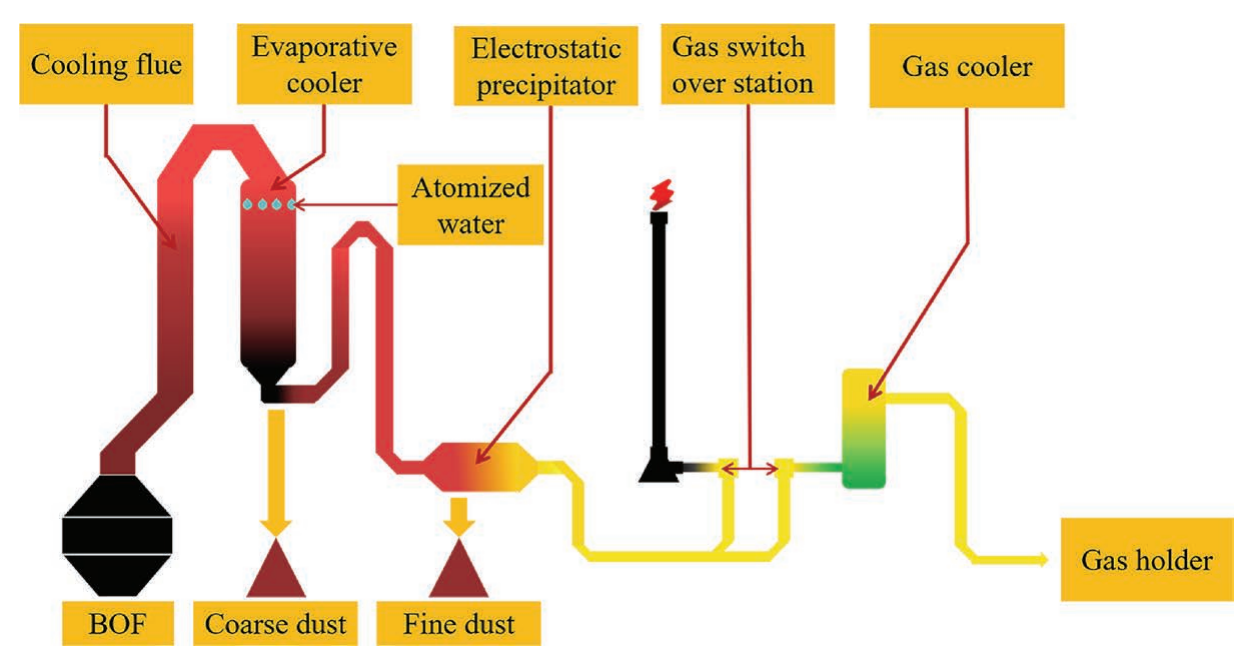

Fig. 1. Schematic diagram of BOF dry flue gas cleaning system. (Online version in color.)

mainly consists of cooling flue, evaporative cooler, electrostatic precipitator and gas cooler, where evaporative cooler plays a significant role. Evaporative cooler sprays water directly into high temperature flue gas, and the water evaporates to atomized water, completes the heat exchange with the flue gas to decrease temperature. Meanwhile, BOF flue gas solid wastes are settled by gravity in evaporative coolers to achieve the first separation of gas and dust. However, the inner wall of evaporative cooler is prone to dust agglomeration, which causes choking of flue gas flow, obstructs the trouble-free operation of BOF dry flue gas cleaning system, and further affects the cleaner production in steelmaking process.

Currently, the reason for dust agglomeration on the inner wall of most evaporative coolers is that the fine BOF dust can flows back with flue gas under the complex flow field inside the cooler. ${ }^{8,9)}$ These dust agglomerates can be eliminated via improving flow field conditions in the evaporative cooler and regularly scouring them with water cannons attached to BOF dry flue gas cleaning system. Nevertheless, in recent years, some steel plants in China have found that dust agglomerates were formed with high zinc content in evaporative coolers of dry flue gas cleaning systems, after extensive use of galvanized steel scrap in steelmaking process. This kind of dust agglomerate is rocky, high hardness, difficult to fall off, and cannot be cleaned with water cannons. It not only affects BOF production, but also causes cleaning systems to clog and not operate normally, further seriously hinders the cleaner production in steelmaking process.

Agglomeration problem caused by the enrichment of zinc-containing substances has been investigated in metallurgy fields. In blast furnaces, zinc vapor enriched in the brick-lined pores of refractory materials forms $\mathrm{ZnO}$ agglomeration, which expands the volume of brick lining and causes destruction. ${ }^{10)}$ Therefore, zinc loading limits are generally set at $100-150 \mathrm{~g}$ per ton liquid iron in blast furnaces. ${ }^{11)}$ In rotary hearth furnaces, the enriched $\mathrm{Zn}$ and $\mathrm{ZnO}$ agglomeration block the flues, resulting in low production efficiency of rotary hearth furnace. Nevertheless, this problem has not been solved for a long time, and restricts the development of rotary hearth technology. In electric furnaces, although the zinc content in dust is high, usually between $14-40 \%,{ }^{12,13)}$ because the electric furnace dust cleaning system adopts bag filter, ${ }^{14)}$ the dust is difficult to form agglomerates and the equipment is easy to clean, therefore, there is no zinc-containing dust agglomerates in the electric furnace dust cleaning system.

If zinc concentration is controlled in basic oxygen furnaces as in blast furnaces, it will inevitably affect the utilization of galvanized steel scrap as an excellent recycling resource. Recently, especially in China, with the transformation of consumption structure, automobile and household appliance industries are growing rapidly, and the output of galvanized sheet is increasing at a high speed, resulting higher utilization rate of galvanized steel scrap in steelmaking plants and an increase of zinc content in BOF flue gas solid wastes. Therefore, the strengthening problem of dust agglomerates in evaporative coolers is gradually rising. In the future, with the increase in the use of galvanized steel scrap, this problem certainly will aggravate, unfortunately, there are currently no other effective controls for it.

Hence, in order to control the dust agglomeration of zinc-containing dust in the evaporative cooler of BOF dry flue gas cleaning system and realize the cleaner production of the steelmaking process, clarifying the characteristics and strengthening mechanism of the dust agglomerates are crucial issues for investigation. In this paper, we first analyzed the dust agglomerate samples via X-ray fluorescence spectrometer (XRF), X-ray diffraction (XRD) and scanning electron microscopy (SEM) to clarify the composition of the main substances that affect the agglomeration strengthening; secondly, through the high-temperature roasting experiment of zinc-containing BOF dust, the influence of zinccontaining substances on dust agglomerates was explained; finally, the strengthening mechanism of dust agglomerates was analyzed, and the methods for keeping down highstrength dust agglomerates in BOF dry flue gas cleaning system was proposed. This study provides a theoretical basis for dust agglomeration research in BOF dry flue gas cleaning systems. It is of positive significance for improving dust agglomeration, ensuring the cleaner production in steelmaking process and promoting environmental protection development of steel enterprises. 


\section{Materials and Methods}

\subsection{Materials}

\subsubsection{BOF Flue Gas Solid Wastes}

Dust agglomerates were produced by the accumulation of BOF flue gas solid wastes in evaporative coolers, so the solid wastes were first analyzed. BOF flue gas solid wastes used in this research was provided by Shanghai Meishan, which was divided into coarse dust and fine dust. The average particle size of coarse dust is $50-70 \mu \mathrm{m}$, and the fine dust is $30-50 \mu \mathrm{m}$.

The chemical composition (Table 1) of BOF dust were measured by X-ray fluorescence spectrometer (Lab Center XRF-1800 manufactured by Shimadzu), and the phase components (Fig. 2) of BOF dust was measured by using a Shimadzu diffractometer with an image plate detector and $\mathrm{Cu}$ $\mathrm{K} \alpha$ radiation $(1.5406 \AA)$, diffraction patterns were collected between $10^{\circ} \leq 2 \theta \leq 90^{\circ}$ at a rate of $1 \% \mathrm{~min}$. It can be seen

Table 1. Chemical composition of BOF dust determined by XRF element analysis (mass\%).

\begin{tabular}{ccccccccc}
\hline Component & $\mathrm{Fe}$ & $\mathrm{Ca}$ & $\mathrm{Si}$ & $\mathrm{Mg}$ & $\mathrm{Zn}$ & $\mathrm{Na}$ & $\mathrm{K}$ & $\mathrm{Cl}$ \\
\hline BOF coarse dust & 38.79 & 18.53 & 1.44 & 4.30 & 2.42 & 0.73 & 0.63 & 0.58 \\
BOF fine dust & 56.09 & 5.76 & 1.13 & 1.13 & 3.58 & - & 0.67 & 0.44 \\
\hline
\end{tabular}
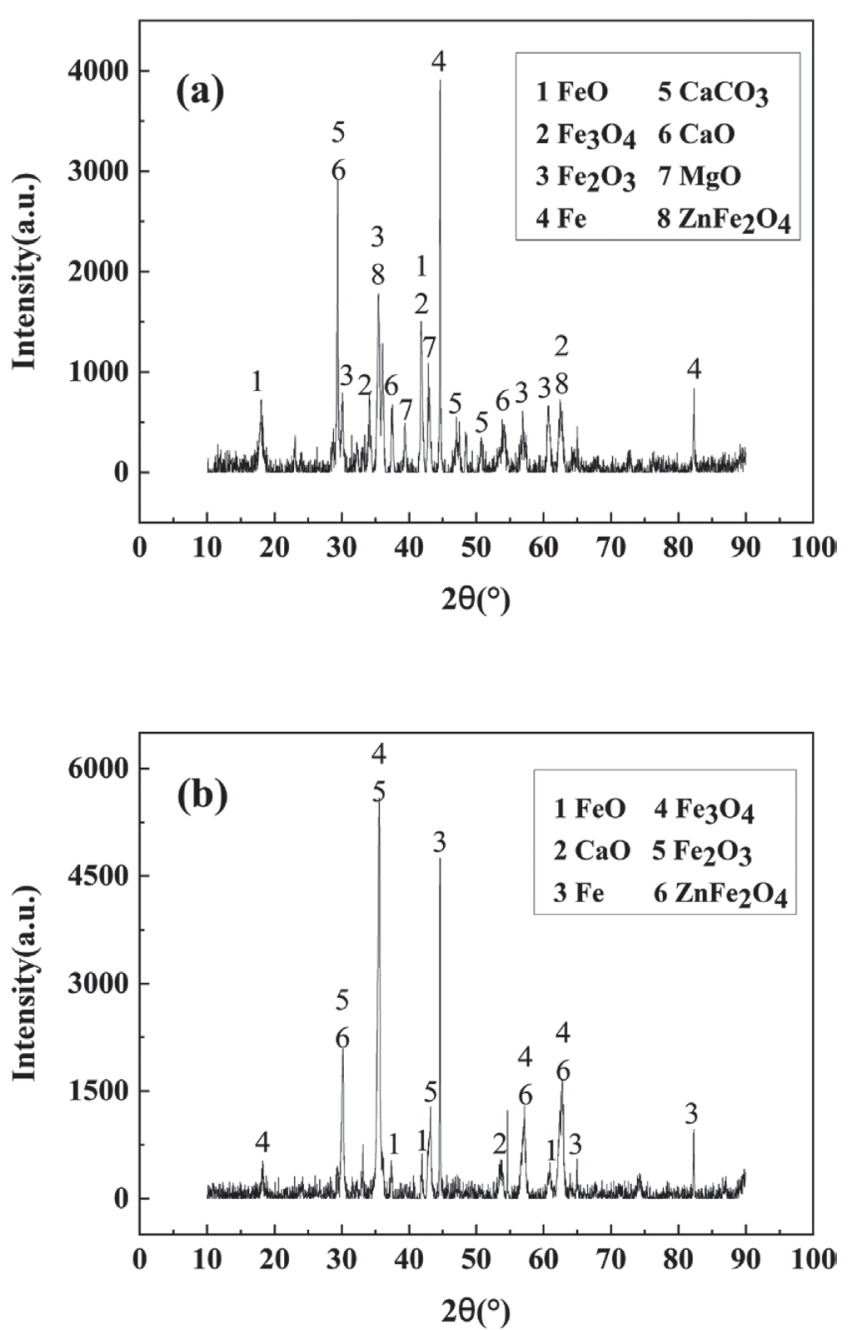

Fig. 2. XRD diffractograms of (a) coarse dust and (b) fine dust. from Table 1 and Fig. 2 that in addition to a large amount of $\mathrm{Fe}$ and $\mathrm{Fe}$ oxide, there is scant amounts of $\mathrm{Zn}$ in BOF dust.

\subsubsection{Dust Agglomerates}

Dust agglomerate samples were taken from the evaporative cooler of BOF dry flue gas cleaning system at Shanghai Meishan. The temperature in evaporative cooler gradually decreased from top to bottom, so the dust agglomerates in the upper part (JL-1), the middle part (JL-2) and the bottom part (JL-3) were separately selected (Fig. 3).

Dust agglomerate samples were crushed and subsequently ground using an agate mortar and passed through a 74 $\mu \mathrm{m}$ sieve prior to XRF and XRD analysis, respectively. The chemical composition and phase components of dust agglomerate samples are shown in Table 2 and Fig. 4.

As can be seen from Table 2, in addition to Fe, there are a certain amount of $\mathrm{Zn}, \mathrm{K}, \mathrm{Na}$, and $\mathrm{Cl}$ in the dust agglomerates. Compared with the chemical composition of BOF dust, the content of $\mathrm{Zn}, \mathrm{K}, \mathrm{Na}$ and $\mathrm{Cl}$ in the dust agglomerates is enriched.

From Fig. 4, one can see that the phase composition of dust agglomerates is related to the temperature in evaporative coolers. In the high temperature zones of evaporative cooler upper and middle parts, the main phases of JL-1 and JL-2 samples are $\mathrm{ZnFe}_{2} \mathrm{O}_{4}$ and $\mathrm{Fe}$-containing substances; in the low temperature zone of evaporative cooler bottom part, the main components of JL-3 sample are $\mathrm{ZnO}$ and Fe-containing substances. The difference between the two is reflected in the Zinc phases. Compared with the low temperature zones, the formation of $\mathrm{ZnFe}_{2} \mathrm{O}_{4}$ in the high temperature zones may involve more complex physical and chemical reactions, so it is necessary to focus on the analysis in the high temperature zones.

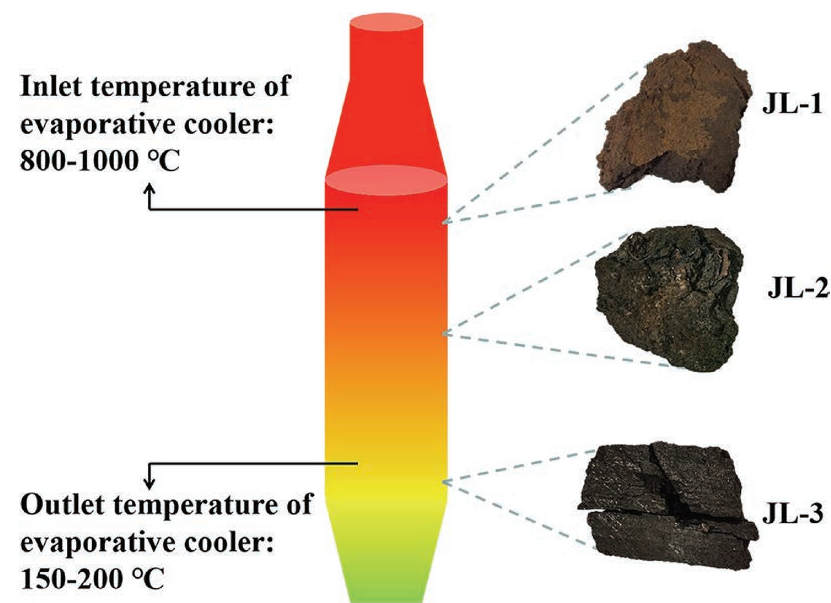

Fig. 3. Dust agglomerate samples at different positions in the evaporative cooler of BOF dry flue gas cleaning system. (Online version in color.)

Table 2. Chemical composition of dust agglomerates determined by XRF element analysis (mass\%).

\begin{tabular}{ccccccccc}
\hline Component & $\mathrm{Fe}$ & $\mathrm{Zn}$ & $\mathrm{K}$ & $\mathrm{Cl}$ & $\mathrm{Na}$ & $\mathrm{Ca}$ & $\mathrm{Mn}$ & $\mathrm{Si}$ \\
\hline JL-1 & 53.27 & 7.83 & 2.75 & 3.17 & 2.32 & 1.34 & 0.98 & 0.67 \\
JL-2 & 55.18 & 6.31 & 2.42 & 2.93 & 2.78 & 2.76 & 0.76 & 0.72 \\
JL-3 & 64.63 & 5.92 & 2.47 & 1.39 & 2.14 & 1.70 & 0.81 & 0.68
\end{tabular}



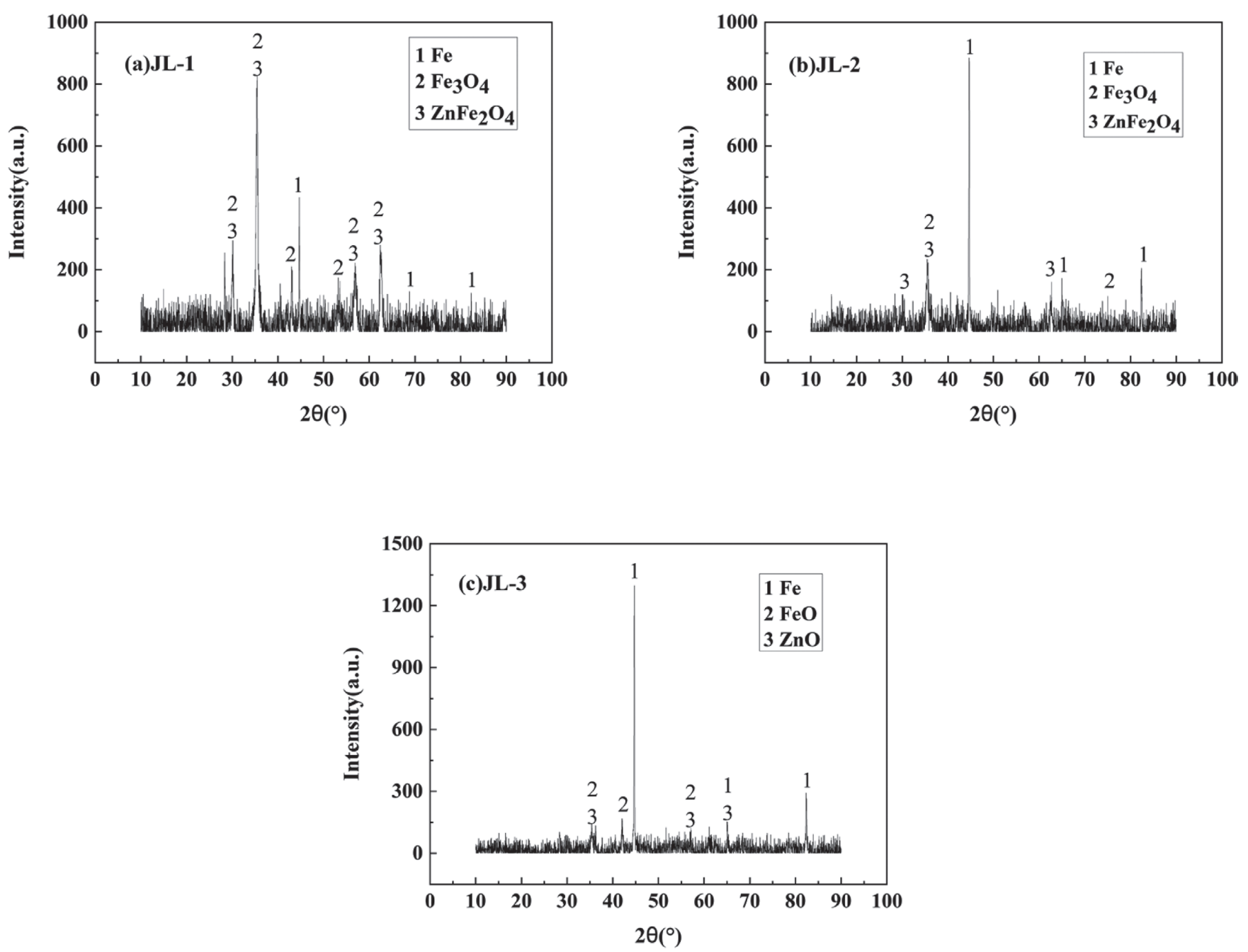

Fig. 4. XRD diffractograms of dust agglomerate samples. (a) JL-1 sample; (b) JL-2 sample; (c) JL-3 sample.

\subsection{Methods}

2.2.1. Analysis of Dust Agglomerate Samples

The dried dust agglomerate samples were sliced, polished, and gold sprayed for microstructure analysis using SEM (VEGA3 SBH manufactured by Tescan, tungsten filament, $30 \mathrm{KV}, 3.0 \mathrm{~nm}$ ).

\subsubsection{High Temperature Roasting Experiment}

Visible from the above analysis results, in addition to the normal $\mathrm{Fe}$ volatiles, there are also $\mathrm{Zn}, \mathrm{K}, \mathrm{Na}, \mathrm{Cl}$ elements enriched in $\mathrm{BOF}$ flue gas solid wastes, which should be $\mathrm{ZnO}$, $\mathrm{KCl}, \mathrm{NaCl}$ according to the material source of $\mathrm{BOF}$ dust.

In order to investigate whether $\mathrm{ZnO}, \mathrm{KCl}$ and $\mathrm{NaCl}$ are the main factors for dust agglomeration strengthening, the cylindrical sample strength of BOF dust with different contents of $\mathrm{ZnO}, \mathrm{KCl}$ and $\mathrm{NaCl}$ was tested by simulating the internal environment of evaporative cooler, and the scheme is shown in Table 3. In order to show the experimental results more clearly, compared with the actual situation, the content of $\mathrm{ZnO}, \mathrm{KCl}$, and $\mathrm{NaCl}$ was increased in the experiment.

The raw materials were mixed with water and poured into a cylindrical mold having a diameter of $20 \mathrm{~mm}$ and a height of $15 \mathrm{~mm}$ to form briquette samples. Then, a manual hydraulic press was used to briquet with a pressure of $1 \mathrm{MPa}$ and a molding time of $0.5 \mathrm{~s}$. The specific sample preparation process is shown in Fig. 5. After the samples were formed,
Table 3. Proportioning scheme of experimental raw materials (mass\%).

\begin{tabular}{ccccccc}
\hline \multirow{2}{*}{$\begin{array}{c}\text { Sample } \\
\text { number }\end{array}$} & \multicolumn{5}{c}{ Constituents } & \\
\cline { 2 - 5 } & Coarse dust & Fine dust & $\mathrm{NaCl}$ & $\mathrm{KCl}$ & $\mathrm{ZnO}$ & \\
\hline S0 & 25 & 75 & - & - & - & 100 \\
S1 & 23 & 73 & 4 & - & - & 100 \\
S2 & 23 & 73 & - & 4 & - & 100 \\
S3 & 21 & 71 & 4 & 4 & - & 100 \\
S4 & 23 & 73 & - & - & 4 & 100 \\
S5 & 19 & 69 & 4 & 4 & 4 & 100 \\
\hline
\end{tabular}

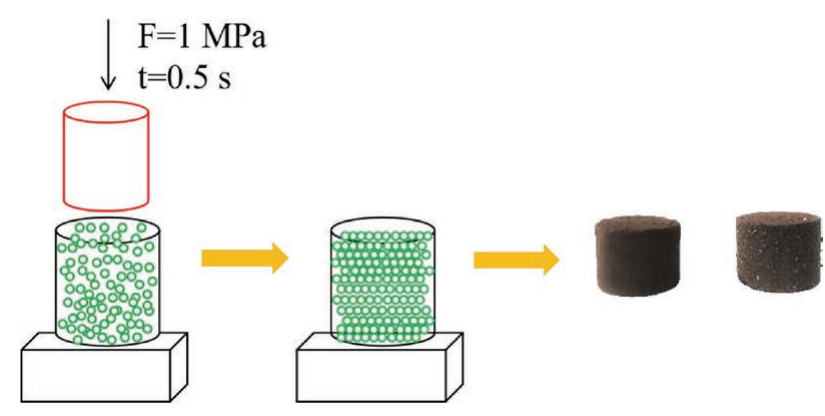

Fig. 5. Schematic diagram of sample preparation process. (Online version in color.) 
they were kept in a muffle furnace heated to $900^{\circ} \mathrm{C}$ for $2 \mathrm{~h}$, and air-cooled to room temperature for compressive strength measuring.

Furthermore, it can be seen from XRD diffractograms in Fig. 4 that the phase composition is various for dust agglomerate samples at different temperatures. Therefore, the study conducted a high temperature roasting experiment on S5 samples in a muffle furnace at $500^{\circ} \mathrm{C}, 600^{\circ} \mathrm{C}, 700^{\circ} \mathrm{C}$, $800^{\circ} \mathrm{C}, 900^{\circ} \mathrm{C}$, and $1000^{\circ} \mathrm{C}$ for $2 \mathrm{~h}$, simulating the effect of the temperature in evaporative cooler on dust agglomerate strength. The samples under different temperatures were aircooled to room temperature for compressive strength testing and XRD pattern analysis.

\section{Results and Discussion}

\subsection{Microscopic Morphologies of Dust Agglomerates}

SEM morphologies of JL-2 sample in evaporative cooler middle part are shown in Fig. 6. The profile of JL-2 sample in Fig. 6(a) is superimposed and hierarchical. The compact and loose layers of uniform thickness have periodic interphase distribution. This distribution may be related to cyclical production of basic oxygen furnaces.

It can be seen from Fig. 6(b) that the substances in each compact layer are closely connected, so there must be a connecting phase which bond the internal substances of compact layer to each other. In terms of macroscopic structure, the high strength of the entire dust agglomerate is inseparable from the connecting phase. Therefore, the connecting phase must be analyzed. As can be seen from a partial enlarged view of the compact layer in Fig. 6(c), the layer is structurally tightness and has blocky crystals distributed.

The SEM-mapping analysis shown in Fig. 7 is performed on the square region. The positions of $\mathrm{Na}$ and $\mathrm{Cl}$ elements are highly coincident with the position of the blocky crystal, so it can be confirmed that the crystal is $\mathrm{NaCl}$. Combining

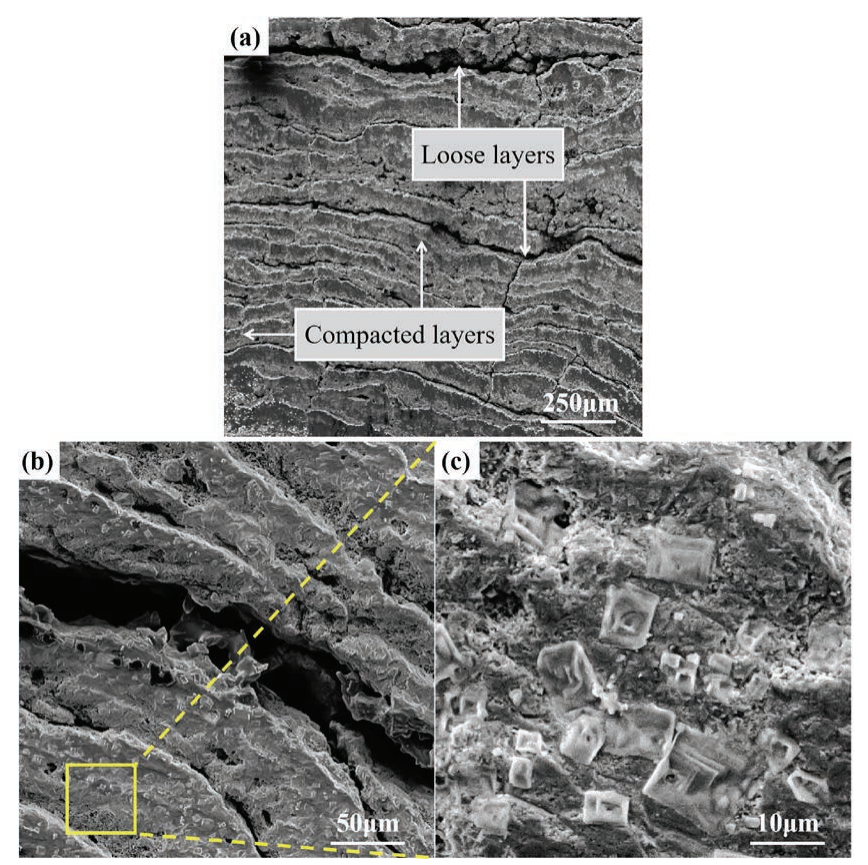

Fig. 6. SEM morphologies of JL-2 dust agglomerate sample. (Online version in color.) the energy dispersive spectrometer (EDS) analysis result for the square region in Table 4, and the XRD diffractograms in Fig. 4, it is found that in the square region, $\mathrm{NaCl}$ is embedded in Fe oxide, and $\mathrm{ZnFe}_{2} \mathrm{O}_{4}$ is dispersed in Fe oxide.

\subsection{Factors Affecting Dust Agglomerate Strength}

The experiment was carried out according the scheme listed in Table 3, and the results are shown in Fig. 8. S0 sample without any added additives has the lowest compressive strength of only $268 \mathrm{~N}$, and the sample strength increases slightly by adding $\mathrm{NaCl}$ and $\mathrm{KCl}(\mathrm{S} 1, \mathrm{~S} 2$, and $\mathrm{S} 3$ samples). On the other hand, the compressive strength of $\mathrm{S} 4$ and $\mathrm{S} 5$ sample containing $\mathrm{ZnO}$ is significantly increased, and $\mathrm{S} 5$ sample with the addition of $\mathrm{NaCl}, \mathrm{KCl}$ and $\mathrm{ZnO}$ has

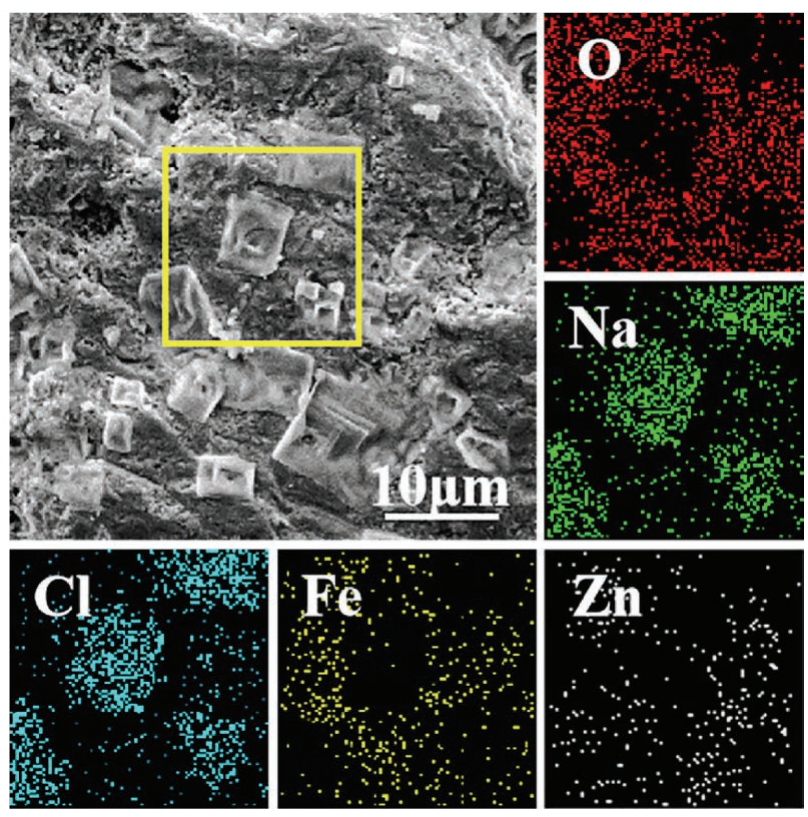

Fig. 7. SEM-mapping images of JL-2 dust agglomerate sample. (Online version in color.)

Table 4. Chemical composition of JL-2 dust agglomerate determined by EDS analysis (mass\%).

\begin{tabular}{cccccc}
\hline Component & $\mathrm{Fe}$ & $\mathrm{Zn}$ & $\mathrm{Cl}$ & $\mathrm{Na}$ & $\mathrm{O}$ \\
\hline Mass percent & 38.23 & 13.89 & 14.18 & 11.55 & 22.14 \\
\hline
\end{tabular}

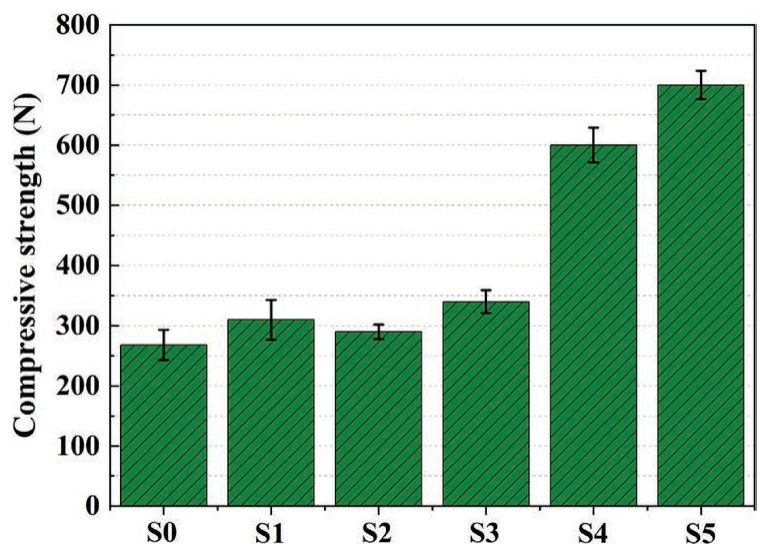

Fig. 8. Sample compressive strength with different raw materials after roasting at $900^{\circ} \mathrm{C}$. (Online version in color.) 
the highest strength of $706 \mathrm{~N}$.

It can be seen that $\mathrm{ZnO}$ has the dominant influence on the sample compressive strength, and the strength of S5 sample is increased by 4 to 5 times relative to S0 sample. Although the samples containing $\mathrm{NaCl}$ and $\mathrm{KCl}$ have a small increase in strength compared with the sample containing $\mathrm{ZnO}$, but comparing S0, S1, S2 and S3 samples, it can be seen that the strength of S0 sample is $268 \mathrm{~N}$, while that of S3 sample reaches $340 \mathrm{~N}$, the strength is increased by about $30 \%$, which has a certain influence on the dust aggregate strength.

The compressive strength of S5 sample after roasting at different temperatures for $2 \mathrm{~h}$ is shown in Fig. 9. One can see that the sample strength increases with rising of temperature, and the growth trend of the strength is steeper between 600 and $700^{\circ} \mathrm{C}$.

Furthermore, it can be seen from XRD diffractograms of $\mathrm{S} 5$ sample at different temperatures in Fig. 10 that $\mathrm{ZnFe}_{2} \mathrm{O}_{4}$ phase exists in the samples with a roasting temperature exceeding $600^{\circ} \mathrm{C}$, and the peak of $\mathrm{ZnFe}_{2} \mathrm{O}_{4}$ phase increases with rising temperature. The results illustrate the effect of temperature on dust agglomerate phases and strength. The higher the temperature, the more the $\mathrm{ZnFe}_{2} \mathrm{O}_{4}$ phase and the higher the strength. The formation of $\mathrm{ZnFe}_{2} \mathrm{O}_{4}$ phase is directly related to dust agglomerate strength. Therefore, the formation process of $\mathrm{ZnFe}_{2} \mathrm{O}_{4}$ phase deserves further study.

\subsection{Strengthening Mechanism of Dust Agglomerates}

Thermodynamic conditions vary widely in BOF dry flue gas cleaning systems due to changes in temperature and flue constituents (Fig. 11). The temperature in evaporative coolers is generally in the range of 150 to $1000^{\circ} \mathrm{C}$, and in this temperature range, $\mathrm{Fe}$ and $\mathrm{Fe}$ oxides in dust agglomerates can not be sintered to increase the strength. ${ }^{15)}$ Therefore, it is necessary to analyze the influence of the substances containing $\mathrm{Zn}^{2+}, \mathrm{Na}^{+}$and $\mathrm{K}^{+}$on dust agglomerate strength.

\subsubsection{Effect of Zinc-containing Substances on Dust Agglomeration}

A certain amount of zinc-containing substances were found from the composition and morphologies of dust agglomerates. Meanwhile, in the high-temperature roasting experiment, zinc-containing substances greatly improved

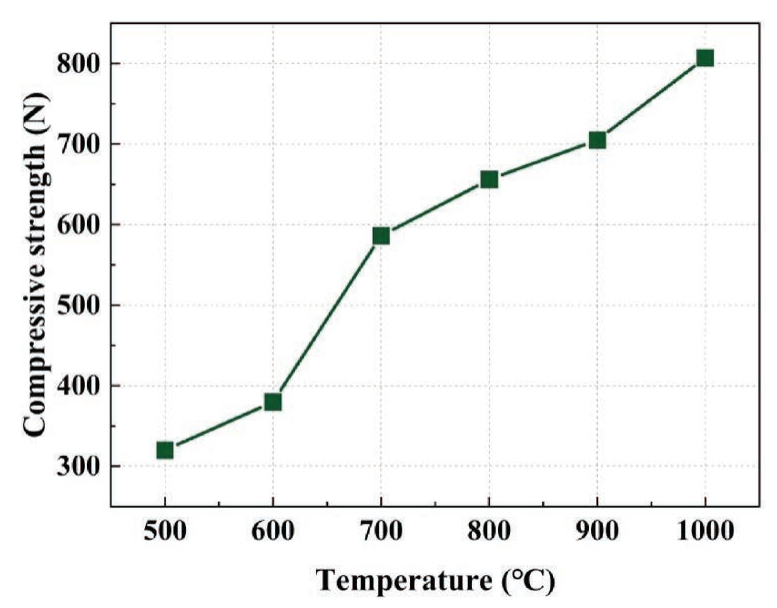

Fig. 9. Relationship between temperature and compressive strength of S5 sample. (Online version in color.) the dust agglomerate strength. Therefore, the transformation process of the zinc-containing substances was analyzed.

The composition of BOF flue gas solid wastes contains zinc due to the addition of galvanized steel scrap during steelmaking. Zinc in the galvanized steel scrap is mainly in the form of elemental $\mathrm{Zn}$ and $\mathrm{ZnO} .^{16,17)} \mathrm{ZnO}$ has a very high melting point $\left(1975^{\circ} \mathrm{C}\right)$ and boiling point $\left(2360^{\circ} \mathrm{C}\right)$, so it exists as a solid in basic oxygen furnace. Since the density of $\mathrm{ZnO}\left(5.606 \mathrm{~g} / \mathrm{cm}^{3}\right)$ is less than liquid steel $(7.0 \mathrm{~g} /$ $\mathrm{cm}^{3}$ ), it will be suspended on the surface of liquid steel, and brought into the slag-metal-gas three-phase emulsified slag via a large amount of $\mathrm{CO}$ gas generated by carbon-oxygen reaction. In the emulsified slag, $\mathrm{ZnO}$ may react with $\mathrm{CO}$ to form elemental $\mathrm{Zn}$. Elemental $\mathrm{Zn}$ has a lower melting point $\left(419.53^{\circ} \mathrm{C}\right)$ and boiling point $\left(907^{\circ} \mathrm{C}\right)$, it will enter the cleaning system with BOF flue gas after vaporization in steelmaking process. The chemical reactions of zinccontaining substances that may occur in BOF dry flue gas cleaning systems are shown in Eqs. (1)-(5).

$$
\begin{array}{r}
\mathrm{ZnO}(\mathrm{s})+\mathrm{CO}(\mathrm{g}) \rightarrow \mathrm{Zn}(\mathrm{g})+\mathrm{CO}_{2}(\mathrm{~g}) \\
2 \mathrm{Zn}(\mathrm{g})+\mathrm{O}_{2}(\mathrm{~g}) \rightarrow 2 \mathrm{ZnO}(\mathrm{s}) \\
\mathrm{ZnO}(\mathrm{s})+\mathrm{Fe}_{2} \mathrm{O}_{3}(\mathrm{~s}) \rightarrow \mathrm{ZnFe}_{2} \mathrm{O}_{4}(\mathrm{~s})
\end{array}
$$

$$
3 \mathrm{ZnO}(\mathrm{s})+2 \mathrm{Fe}_{3} \mathrm{O}_{4}(\mathrm{~s})+\mathrm{CO}_{2}(\mathrm{~g}) \rightarrow 3 \mathrm{ZnFe}_{2} \mathrm{O}_{4}(\mathrm{~s})+\mathrm{CO}(\mathrm{g})
$$

$$
\mathrm{ZnO}(\mathrm{s})+2 \mathrm{FeO}(\mathrm{s})+\mathrm{CO}_{2}(\mathrm{~g}) \rightarrow \mathrm{ZnFe}_{2} \mathrm{O}_{4}(\mathrm{~s})+\mathrm{CO}(\mathrm{g})
$$

In order to determine whether these chemical reactions occurred in the cleaning systems, Factsage 6.4 software was used for thermodynamic analysis. Figure 12 shows the relationship between the Gibbs free energy $\Delta_{\mathrm{r}} \mathrm{G}_{\mathrm{T}}{ }^{\theta}$ of different reactions and temperatures. It can be seen from Fig. 12 that the Gibbs free energy of Eq. (1) is greater than zero in the temperature range of BOF dry flue gas cleaning system, indicating that $\mathrm{ZnO}$ cannot be reduced to elemental $\mathrm{Zn}$ by $\mathrm{CO}$. Therefore, $\mathrm{ZnO}$ in basic oxygen furnace will remain in the slag, and elemental $\mathrm{Zn}$ will enter the cleaning systems as zinc vapor at a high temperature.

After zinc vapor formed under the high temperature enters the cleaning system with flue gas, and its transformation process is shown in Fig. 13:

i) Gaseous zinc atoms collide and and coagulate due to Brownian motion. Therefore, both gaseous zinc atoms and agglomerated solid zinc particles are present in the zinc vapor. $^{18,19)}$

ii) From BOF outlet to cooling flue, gaseous zinc atoms react rapidly with $\mathrm{O}_{2}$ to form $\mathrm{ZnO}$ (Eq. (2)) under BOF oxygen blowing, ${ }^{20)}$ and $\mathrm{ZnO}$ grows by heterogeneous nucleation on the surface of solid zinc particles. ${ }^{21)}$ Because of the compactness of $\mathrm{ZnO}$ layer, most of zinc atoms are not completely oxidized and still remain in elementary substance.

iii) After entering the evaporative cooler, the temperature of gaseous zinc atoms drops below the boiling point, molten liquid zinc begins to encapsulate $\mathrm{ZnO}$ and solid zinc particles.

iv) The liquid zinc containing $\mathrm{ZnO}$ adheres to the surrounding $\mathrm{BOF}$ dust particles, causing $\mathrm{ZnO}$ to contact with 

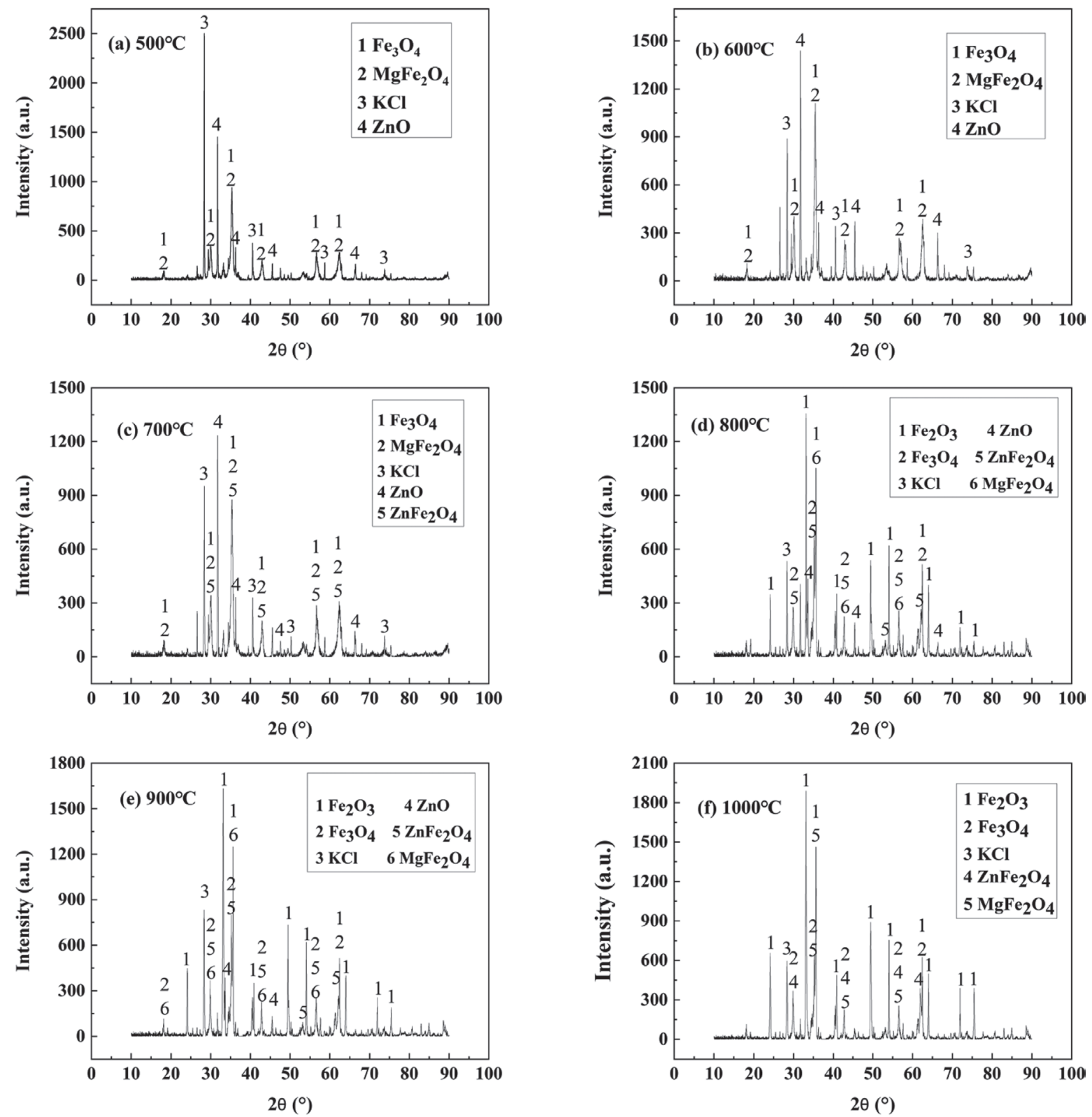

Fig. 10. XRD diffractograms of S5 sample at (a) $500^{\circ} \mathrm{C}$, (b) $600^{\circ} \mathrm{C}$, (c) $700^{\circ} \mathrm{C}$, (d) $800^{\circ} \mathrm{C}$, (e) $900^{\circ} \mathrm{C}$ and (f) $1000^{\circ} \mathrm{C}$ roasting temperatures.

$\mathrm{Fe}_{2} \mathrm{O}_{3}$ in $\mathrm{BOF}$ dust. It can be seen from the thermodynamic analysis in Fig. 12 that $\mathrm{ZnO}$ can react with $\mathrm{Fe}_{2} \mathrm{O}_{3}$ to form $\mathrm{ZnFe}_{2} \mathrm{O}_{4}$.

From the perspective of dynamics, due to the tiny bonding strength between $\mathrm{ZnO}$ and $\mathrm{Fe}_{2} \mathrm{O}_{3}$ particles, the particles can only vibrate in a small range at the equilibrium position, so the solid phase reaction rate is tardy, and $\mathrm{ZnFe}_{2} \mathrm{O}_{4}$ cannot be formed in a short time. However, under the high temperature, the solid particles acquire the energy necessary to participate in the chemical reaction and then can diffuse to other solid surfaces in contact, resulting in solid phase reaction between $\mathrm{ZnO}$ and $\mathrm{Fe}_{2} \mathrm{O}_{3}$.

Previous literature ${ }^{22)}$ has indicated that $\mathrm{ZnO}$ begins to react with $\mathrm{Fe}_{2} \mathrm{O}_{3}$ to form $\mathrm{ZnFe}_{2} \mathrm{O}_{4}$ above $600^{\circ} \mathrm{C}$, and the reaction rate accelerates with the rising of temperature. The XRD diffractograms in Fig. 10 also demonstrates this conclusion. Since $\mathrm{ZnFe}_{2} \mathrm{O}_{4}$ belongs to equiaxed crystal system in lattice structure, the host or support structure is oxygen ion, chemical bonds between the ions are strong, and atomic stacking is tight, so the physical and chemical properties of $\mathrm{ZnFe}_{2} \mathrm{O}_{4}$ are extremely stable. ${ }^{23,24)}$ After the formation of $\mathrm{ZnFe}_{2} \mathrm{O}_{4}$ with exceedingly high strength, it chemically bonds with the surrounding BOF dust particles to form a dense agglomerate, which increases the dust agglomerate strength.

The unoxidized liquid zinc reacts in $\mathrm{CO} / \mathrm{CO}_{2}$ atmosphere of evaporative cooler to form $\mathrm{ZnO}$ (Eq. (6)), and then continues to react with the adsorbed $\mathrm{Fe}_{2} \mathrm{O}_{3}$ to form $\mathrm{ZnFe}_{2} \mathrm{O}_{4}$, thereby further increasing the dust agglomerate strength.

$$
2 \mathrm{Zn}(\mathrm{l})+2 \mathrm{CO}_{2} \rightarrow 2 \mathrm{ZnO}(\mathrm{s})+2 \mathrm{CO}
$$

In addition, the presence of $\mathrm{ZnFe}_{2} \mathrm{O}_{4}$ in XRD diffractograms (Figs. 4(a) and 4(b)) demonstrates the occurrence of these reactions in the evaporative cooler with high temperature. Nevertheless, $\mathrm{ZnO}$ is found in Fig. 4(c), indicating that the temperature in evaporative cooler bottom part is lower, which is not conducive to the formation of $\mathrm{ZnFe}_{2} \mathrm{O}_{4}$. Since the liquid zinc adheres to BOF dust particles, the dust par- 
ticles are enriched on the inner wall of evaporative cooler. Due to the high fluidity of liquid zinc, dust particles are wetted or wrapped after contact with it, and the new phase $\mathrm{ZnO}$ formed becomes a binder phase between the dust particles.

It is concluded that due to the formation of $\mathrm{ZnFe}_{2} \mathrm{O}_{4}$ binder phase which is extremely stable in physical and chemical properties, dense in atomic stacking, and strong in chemical bonds between ions, the dust agglomerates in the upper and middle high temperature zones of evaporative cooler are high in compactness and is not easy to fall off under gravity. While the dust agglomeration strengthening in the bottom low temperature zone is caused by the formation of the new binder phase $\mathrm{ZnO}$, but $\mathrm{ZnO}$ binder phase is different from the chemical adsorption generated by $\mathrm{ZnFe}_{2} \mathrm{O}_{4}$ phase, and the agglomerate strength is relatively weak.

\subsubsection{Effect of Substances Containing $\mathrm{Na}^{+}$and $\mathrm{K}^{+}$on Dust Agglomeration}

The main elements of dust agglomerates in Table 1 contain $\mathrm{Na}, \mathrm{K}$, and $\mathrm{Cl}$, and $\mathrm{NaCl}$ crystals are found from SEM-mapping analysis in Fig. 7. Furthermore, it can be seen from the high temperature roasting experiment shown in Fig. 8 that $\mathrm{NaCl}$ and $\mathrm{KCl}$ have a certain degree of improvement on dust agglomerate strength.

Both $\mathrm{NaCl}$ and $\mathrm{KCl}$ are low melting point materials. The melting point and boiling point of $\mathrm{NaCl}$ are $801^{\circ} \mathrm{C}$ and $1412^{\circ} \mathrm{C}$, respectively, and $\mathrm{KCl}$ is $773^{\circ} \mathrm{C}$ and $1420^{\circ} \mathrm{C}$, respectively. In BOF production process, due to the addition of various excipients, it will contain $\mathrm{Na}, \mathrm{K}, \mathrm{Cl}$ impurities. Under the high temperature, $\mathrm{Na}, \mathrm{K}$, and $\mathrm{Cl}$ impurities will volatilize in the form of $\mathrm{NaCl}$ and $\mathrm{KCl}$ gases, and then entering the cleaning system along with the flue gas. After reaching the cooling flue, $\mathrm{NaCl}$ and $\mathrm{KCl}$ gases are liquefied into suspended droplets, and entrain the surrounding dust particles into the evaporative cooler. Under the thrust of

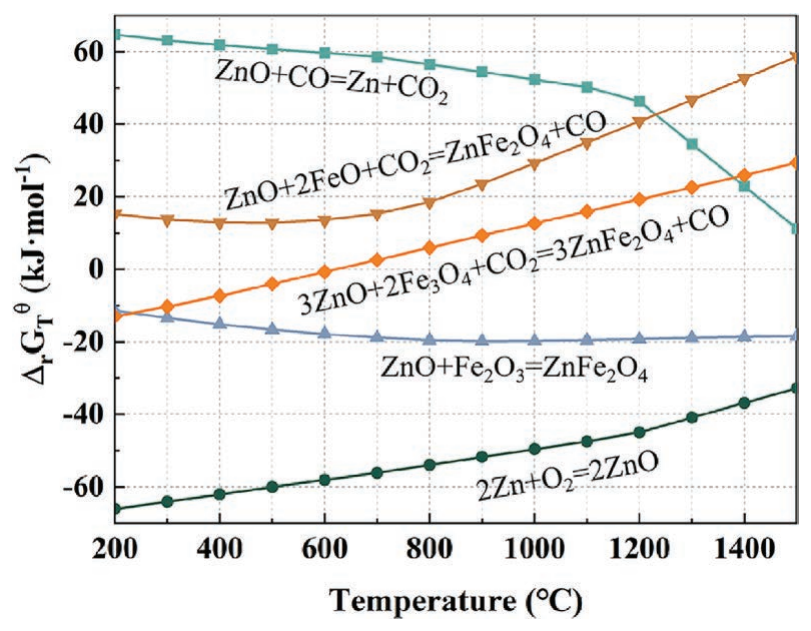

Fig. 12. Relationship between Gibbs free energy $\Delta_{\mathrm{r}} \mathrm{G}_{\mathrm{T}}{ }^{\theta}$ and temperature in different chemical reactions of $\mathrm{Zn}$-containing substances in BOF dry flue gas cleaning system. (Online version in color.)

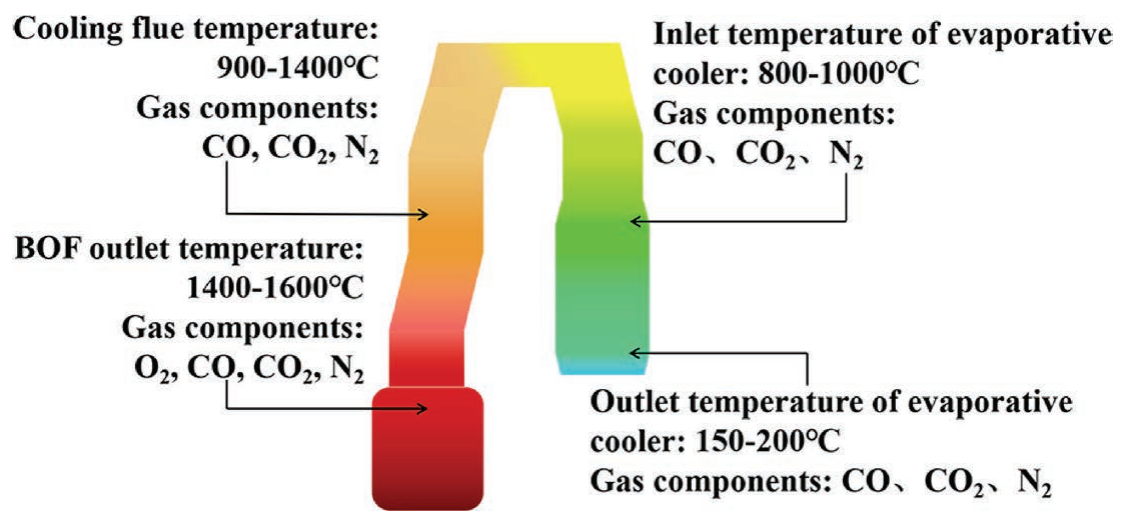

Fig. 11. Local temperature and flue constituents of BOF dry flue gas cleaning system. (Online version in color.)

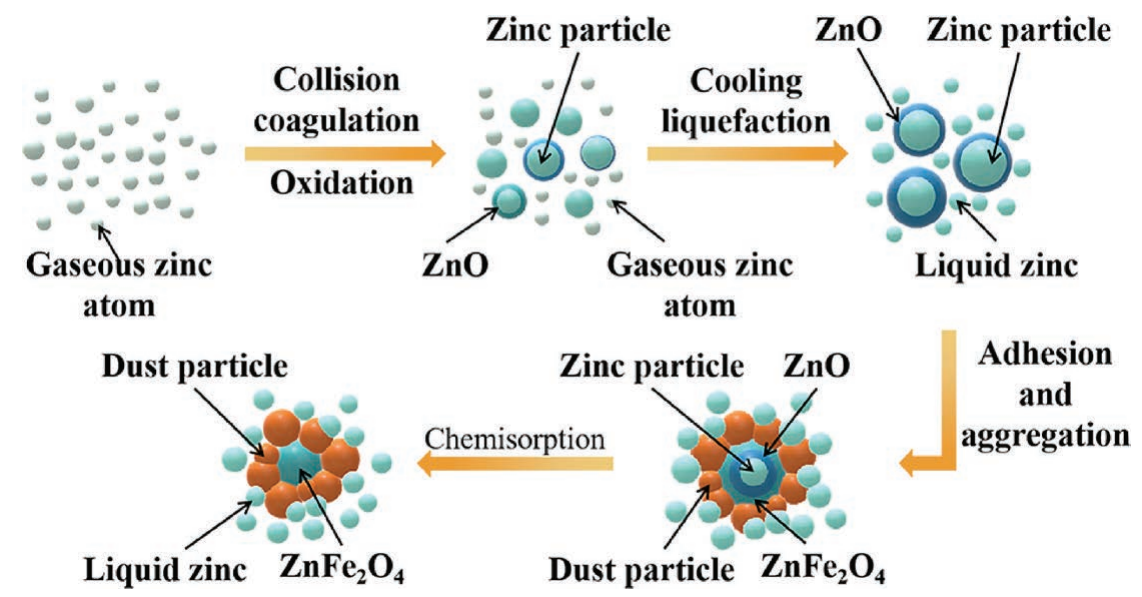

Fig. 13. Transformation process of $\mathrm{Zn}$-containing substances in BOF dry flue gas cleaning system. (Online version in color.) 
atomized water in the evaporative cooler, $\mathrm{NaCl}$ and $\mathrm{KCl}$ adhere to the inner wall. Because of the low temperature, the liquid $\mathrm{NaCl}$ and $\mathrm{KCl}$ solidify into solid phases, and at this temperature, solid state sintering of $\mathrm{NaCl}$ and $\mathrm{KCl}$ occurs, ${ }^{25)}$ which increases the dust agglomerate strength.

\subsubsection{Dust Agglomeration Strengthening Mechanism}

Based on the above investigations, the dust agglomeration strengthening mechanism in the evaporative cooler can be illustrated by Fig. 14. After BOF flue gas solid wastes generated in steelmaking process enter the evaporative cooler, they move to the inner wall of evaporative cooler under the lateral thrust of atomized water. The molten liquid zinc containing $\mathrm{ZnO}$ is first adsorbed on the inner wall of evaporative cooler, and $\mathrm{ZnO}$ reacts with $\mathrm{Fe}_{2} \mathrm{O}_{3}$ in dust particles to form a dense $\mathrm{ZnFe}_{2} \mathrm{O}_{4}$ phase. $\mathrm{ZnFe}_{2} \mathrm{O}_{4}$ chemically bonds with the surrounding dust particles to form a dense aggregate, which leads to an increase in the agglomerate strength, and the aggregates continue to accumulate to form compacted layers. If low melting point substances such as $\mathrm{NaCl}$ and $\mathrm{KCl}$ are present in $\mathrm{BOF}$ dust, they exist in a solid form under the temperature condition of evaporative cooler, and the dust agglomerate strength is increased by solid state sintering.

Since BOF production is cyclical, when the new solid wastes enter the evaporative cooler, they will adhere to the original dust agglomerate layers. However, the surface of original layers are rough, and the temperature and composition of new and old layers are also different, resulting in the generation of loose layers. New compacted layers are formed on the loose layers, thereby circulating and the dust agglomerate layers are continuously thickened.

\subsection{Control of Dust Agglomeration Strengthening}

Visible from the above analysis, the main reason for dust agglomeration strengthening in evaporative coolers is that $\mathrm{ZnO}$ and $\mathrm{Fe}_{2} \mathrm{O}_{3}$ form a dense $\mathrm{ZnFe}_{2} \mathrm{O}_{4}$ binder phase through solid phase reaction. Therefore, controlling the formation of $\mathrm{ZnFe}_{2} \mathrm{O}_{4}$ is the key to avoiding dust agglomeration strengthening.

The initial solid phase reaction temperature of $\mathrm{ZnO}$ and $\mathrm{Fe}_{2} \mathrm{O}_{3}$ to form $\mathrm{ZnFe}_{2} \mathrm{O}_{4}$ is $600^{\circ} \mathrm{C}$, and the reaction rate increases with the rising of temperature, while the temperature of BOF flue gas solid wastes can reach $800-1000^{\circ} \mathrm{C}$ when entering evaporative coolers. Therefore, the temperature in evaporative coolers can be lowered without affecting the flue gas cleaning effect, thereby reducing the solid phase reaction rate, decreasing the generation of $\mathrm{ZnFe}_{2} \mathrm{O}_{4}$, making it impossible to consolidate with BOF dust particles, and avoiding dust agglomeration strengthening.

Furthermore, solid $\mathrm{NaCl}$ and $\mathrm{KCl}$ will sinter in evaporative coolers. The solid state sintering of $\mathrm{NaCl}$ and $\mathrm{KCl}$ is mainly carried out by evaporation-viscoaggregation, ${ }^{26,27)}$ and the sintering kinetics formula can be expressed as:

$$
\frac{\mathrm{x}}{r}=\left(\frac{3 \sqrt{\pi} \gamma M^{\frac{3}{2}} \rho_{0}}{\sqrt{2} R^{\frac{3}{2}} T^{\frac{3}{2}} d^{2}}\right)^{\frac{1}{3}} r^{\frac{2}{3}} t^{\frac{1}{3}}
$$

Where, $r$ is the radius of particle, $\mathrm{m} ; \gamma$ is the surface tension, $\mathrm{N} / \mathrm{m} ; \mathrm{M}$ is the relative molecular mass; $\rho_{0}$ is the surface vapor pressure, $\mathrm{Pa} ; \mathrm{R}$ is the gas constant, $\mathrm{J} /(\mathrm{mol} \cdot \mathrm{K})$; $\mathrm{T}$ is the sintering temperature, $\mathrm{K} ; \mathrm{d}$ is the density, $\mathrm{kg} / \mathrm{m}^{3} ; \mathrm{t}$ is the sintering time, $\mathrm{s}$.

It can be seen from Eq. (7) that as the sintering temperature $\mathrm{T}$ elevates, the surface vapor pressure $\rho_{0}$ will increase to promote sintering. Therefore, the sintering strength of $\mathrm{NaCl}$ and $\mathrm{KCl}$ can be lowered by keeping down the temperature in evaporative coolers. In addition, it is necessary to strictly control the content of $\mathrm{Na}^{+}$and $\mathrm{K}^{+}$contained in basic oxygen furnaces, and to reduce the formation of low melting point substances from the source.

The research carried out experiments using the dry flue gas cleaning system of 150 t BOF in Shanghai Meishan to reduce the inlet temperature of evaporative cooler to less than $850^{\circ} \mathrm{C}$, and control $\mathrm{Na}^{+}$and $\mathrm{K}^{+}$content in the early stage of steelmaking to be less than $0.5 \%$, respectively. Through a whole year of production application, the dust agglomerates in the evaporative cooler were significant reduced, and the cleaning system was not affected by dust agglomeration strengthening.

Consequently, the control methods proposed based on the dust agglomeration strengthening are validated to be effective. The methods ensure the cleaner production in

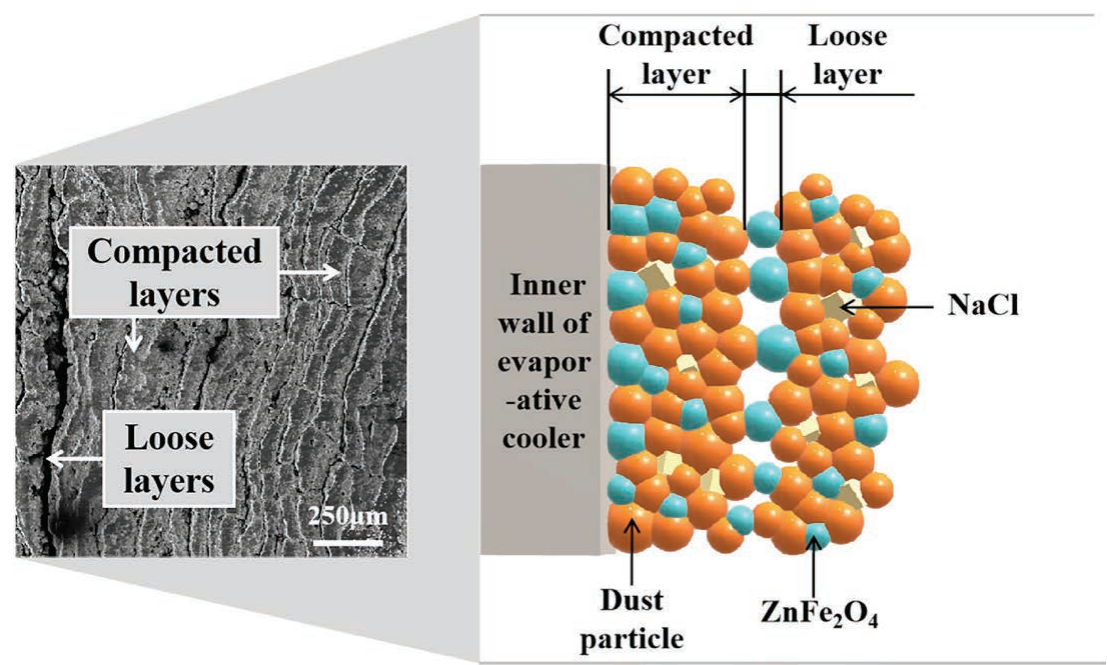

Fig. 14. Schematic diagram of dust agglomeration strengthening in evaporative coolers. (Online version in color.) 
steelmaking process and can be used for long-term industrial applications.

\section{Conclusions}

This paper presents the characteristics of zinc-containing dust agglomerates in the evaporative cooler of BOF flue gas cleaning system agglomerates and the strengthening mechanism, as well as proposes effective control methods. From the results obtained in this paper the following conclusions can be drawn:

- The high strength dust agglomerates in the evaporative cooler of BOF dry flue gas cleaning system consist of compact and loose layers, and the compact layers contain $\mathrm{ZnFe}_{2} \mathrm{O}_{4}, \mathrm{NaCl}$ and $\mathrm{KCl}$.

- After $\mathrm{ZnO}$ reacts with $\mathrm{Fe}_{2} \mathrm{O}_{3}$ at a high temperature above $600^{\circ} \mathrm{C}$ to form tightly $\mathrm{ZnFe}_{2} \mathrm{O}_{4}$ phase, chemical adsorption of $\mathrm{ZnFe}_{2} \mathrm{O}_{4}$ with BOF dust particles is the primary cause of dust agglomeration strengthening in evaporative coolers. Solid state sintering of low melting point substances containing $\mathrm{Na}^{+}$and $\mathrm{K}^{+}$promotes dust agglomeration strengthening.

- Decreasing the temperature in evaporative coolers, reducing the amount of $\mathrm{ZnFe}_{2} \mathrm{O}_{4}$ produced, and controlling the content of low melting point substances containing $\mathrm{Na}^{+}$ and $\mathrm{K}^{+}$in BOF flue gas solid wastes can effectively improve dust agglomeration in evaporative coolers, optimize the environment of cleaning system, and ensure the cleaner production in steelmaking process.

\section{Acknowledgments}

The authors wish to thank National Natural Science Foundation of China (Grant No. 51574050) for supporting this research. The authors wish to express their gratitude to the industrial experimental site provided by Shanghai Meishan Iron and Steel Co., Ltd., the technical assistance provided by Jianguo Hong and Wenhua Yan, and the workers involved in industrial experiments.

\section{REFERENCES}

1) World Steel Association: Steel Statistical Yearbook 2019, https:// www.worldsteel.org/en/dam/jcr:7aa2a95d-448d-4c56-b62bb2457f067cd9/SSY19\%2520concise\%2520version.pdf, (accessed 2020-10-08).

2) A. Gritzan and D. Neuschütz: Steel Res., 72 (2001), 324. http://doi. org/10.1002/srin.200100126

3) M. L. Sammut, J. Rose, A. Masion, E. Fiani, M. Depoux, A. Ziebel, J.
L. Hazemann, O. Proux, D. Borschneck and Y. Noack: Chemosphere, 70 (2008), 1945. https://doi.org/10.1016/j.chemosphere.2007.09.063

4) G. Wang, Q. G. Xue, Y. X. Zhao, X. F. She and J. S. Wang: Ironmaking Steelmaking, 41 (2014), 591. https://doi.org/10.1179/174328 1213Y.0000000171

5) H. C. Henschen: J. Air Pollut. Control Assoc., 18 (1968), 338. https:// doi.org/10.1080/00022470.1968.10469138

6) A. E. Knieper and J. D. Riley: Iron Steel Eng., 67 (1990), 39.

7) H. Zhou, F. M. Zhang, D. G. Zhang and L. Y. Zhang: Adv. Mater. Res., 610-613 (2012), 1422. https://doi.org/10.4028/www.scientific. net/amr.610-613.1422

8) C. Chigwedu, J. Kempken, A. Ploch and W. Pluschkell: Steel Res., 66 (1995), 341. https://doi.org/10.1002/srin.199501135

9) B. O. de Almeida Santos, B. T. Maia, F. S. Garajau, M. de Souza Lima Guerra, H. L. de Freitas, J. G. Torres, R. Huebner and R. P. Tavares: J. Mater. Res. Technol., 1 (2012), 21. https://doi. org/10.1016/S2238-7854(12)70005-4

10) G. M. Stepin, L. S. Mkrtchan, I. V. Dovlyadov and I. K. Borshchevskii: Metallurgist, 45 (2001), 382. https://doi. org/10.1023/A:1017928207855

11) N. Ma: J. Clean. Prod., 112 (2016), 4497. https://doi.org/10.1016/ j.jclepro.2015.07.009

12) T. Havlík, B. V. e Souza, A. M. Bernardes, I. A. H. Schneider and A. Miškufová: J. Hazard. Mater., 135 (2006), 311. https://doi.org/ 10.1016/j.jhazmat.2005.11.067

13) T. Sofilić, A. Rastovčan-Mioč, Š. Cerjan-Stefanović, V. Novosel-Radović and M. Jenko: J. Hazard. Mater., 109 (2004), 59. https://doi.org/10.1016/j.jhazmat.2004.02.032

14) G. A. Pettit: J. Air Pollut. Control Assoc., 13 (1963), 607. https://doi. org/10.1080/00022470.1963.10468228

15) P. K. Singh, A. Lava Kumar, P. K. Katiyar and R. Maurya: J. Mater. Res. Technol., 6 (2017), 289. https://doi.org/10.1016/ j.jmrt.2016.11.005

16) T. E. Graedel, D. van Beers, M. Bertram, K. Fuse, R. B. Gordon, A. Gritsinin, E. M. Harper, A. Kapur, R. J. Klee, R. Lifset, L. Memon and S. Spatari: J. Ind. Ecol., 9 (2005), 67. https://doi.org/ 10.1162/1088198054821573

17) X. Guo, J. Zhong, Y. Song and Q. Tian: Resour. Conserv. Recycl., 54 (2010), 171. https://doi.org/10.1016/j.resconrec.2009.07.013

18) M. Kitano, T. Hamabe, S. Maeda and T. Okabe: J. Cryst. Growth, 102 (1990), 965. https://doi.org/10.1016/0022-0248(90)90867-K

19) R. Wu, C. Xie, H. Xia, J. Hu and A. Wang: J. Cryst. Growth, 217 (2000), 274. https://doi.org/10.1016/S0022-0248(00)00506-6

20) G. V. Chertihin and L. Andrews: J. Chem. Phys., 106 (1997), 3457. https://doi.org/10.1063/1.473441

21) Y. F. Chen, C. H. Peng, S. H. Yang and M. T. Tang: Chin. J. Nonferr. Met., 15 (2005), 133 (in Chinese). https://doi.org/10.3321/ j.issn:1004-0609.2005.01.023

22) M. M. Rahman, S. B. Khan, M. Faisal, A. M. Asiri and K. A. Alamry: Sens. Actuators B, 171-172 (2012), 932. https://doi.org/10.1016/ j.snb.2012.06.006

23) M. Xu, J. Yang, S. Ma and H. Xiao: Mater. Rev., 30 (2016), 79 (in Chinese).

24) C. Yao, Q. Zeng, G. F. Goya, T. Torres, J. Liu, H. Wu, M. Ge, Y Zeng, Y. Wang and J. Z. Jiang: J. Phys. Chem. C, 111 (2007), 12274. https://doi.org/10.1021/jp0732763

25) M. Broström, S. Enestam, R. Backman and K. Mäkelä: Fuel Process. Technol., 105 (2013), 142. https://doi.org/10.1016/ j.fuproc.2011.08.006

26) R. L. Coble: J. Appl. Phys., 32 (1961), 793. https://doi.org/ $10.1063 / 1.1736108$

27) W. D. Kingery and B. Françis: J. Am. Ceram. Soc., 48 (1965), 546. https://doi.org/10.1111/j.1151-2916.1965.tb14665.x 